\title{
Afe Adogame (eds.), The Public Face of African New Religious Movements. Imagining the Religious "Other"
}

Farnham, Ashgate, coll. "Ashgate Inform Series on Minority Religions and Spiritual Movements", 2014, 300 p.

\section{Alfonso Perez-Agote}

\section{OpenEdition}

\section{Journals}

Édition électronique

URL : http://journals.openedition.org/assr/27270

DOI : $10.4000 /$ assr. 27270

ISSN : $1777-5825$

\section{Éditeur}

Éditions de l'EHESS

Édition imprimée

Date de publication : 1 octobre 2015

Pagination : 239

ISBN : 978-2-7132-2515-4

ISSN : 0335-5985

\section{Référence électronique}

Alfonso Perez-Agote, «Afe Adogame (eds.), The Public Face of African New Religious Movements. Imagining the Religious "Other" », Archives de sciences sociales des religions [En ligne], 172 I octobredécembre, mis en ligne le 13 mai 2016, consulté le 24 septembre 2020. URL : http:// journals.openedition.org/assr/27270; DOI : https://doi.org/10.4000/assr.27270

Ce document a été généré automatiquement le 24 septembre 2020

(c) Archives de sciences sociales des religions 


\section{Afe Adogame (eds.), The Public Face of African New Religious Movements. Imagining the Religious "Other"}

Farnham, Ashgate, coll. "Ashgate Inform Series on Minority Religions and Spiritual Movements“, 2014, 300 p.

Alfonso Perez-Agote

\section{RÉFÉRENCE}

Afe Adogame (eds.), The Public Face of African New Religious Movements. Imagining the Religious "Other", Farnham, Ashgate, coll. "Ashgate Inform Series on Minority Religions and Spiritual Movements“, 2014, 300 p.

1 Ce livre, édité par Afe Adogame, professeur à l'université d'Edimbourg, contient, après l'introduction de l'éditeur, treize chapitres sur divers cas de mouvements religieux de la diaspora africaine.

2 Dans son introduction, Adogame estime que la croissance des migrations internationales et les révolutions technologiques dans les médias et dans les transports ont causé - en Europe, en Amérique et en Asie - l'expansion de nouveaux mouvements religieux africains. La présence de ceux-ci dans la sphère publique a été traitée avec profusion par les médias de masse, plutôt que par des chercheurs en sciences sociales spécialisés dans les nouveaux mouvements religieux. Cela a contribué à établir une certaine image publique de ces mouvements, en mettant l'accent sur la dimension exotique et le sensationnalisme. Pour l'auteur, le manque d'intérêt académique est déterminé par plusieurs raisons: parce que les nouveaux mouvements religieux africains sont considérés comme quelque chose de marginal dans le paysage religieux de l'Occident; parce qu'ils ne rentrent pas facilement dans les catégories et les types 
utilisés par les chercheurs occidentaux; et aussi parce qu'ils ne produisent pas des scandales publics ou des risques à une échelle suffisante pour susciter l'intérêt. Des études sociologiques pourraient aider à renouveler l'image publique de ces mouvements.

Les treize cas contenus dans le livre permettent de nous approcher de certains mouvements religieux africains qui se développent au sein des sociétés non africaines. Une grande partie des cas se situe dans l'Europe. Un chapitre (Aurélien Mokoko Gampiot et Cécile Coquet-Mokoko) est dédié à l'étude des dynamiques transnationales des noirs juifs en France, à travers l'analyse de la Fraternité Judéo-noire comme un outil pour la solidarité et le sentiment d'appartenance, tant à l'intérieur de la communauté juive française que de la société française en général. Un autre travail (Garnet Parris) se situe en Allemagne, abordant l'influence de la culture allemande et des identités et des cultures nationales africaines dans les processus de fondation des églises africaines. Puis un chapitre (Anne Kubai) explique comment, en Suède, la spiritualité chrétienne africaine est utilisée comme mécanisme d'organisation dans le déracinement de la migration. Enfin en ce qui concerne l'Europe, le livre contient quelques chapitres relatifs à la Grande-Bretagne. L'un (Abel Ugba) se réfère au christianisme de la majorité noire en Grande-Bretagne, comprenant une variété d'églises qui ne font pas partie de dénominations protestantes de l'Église d'Angleterre et qui sont formées et dirigées par des Africains noirs venus d'Afrique ou des îles des Caraïbes; ils cherchent une alternative à l'occidentalisation historique menée par les Européens et les Américains. Le travail d'Israël Olofinjana est également lié à la critique de l'occidentalisation développée par certains mouvements tels que le Kingsway International Christian Center, dont le chef de file nigérian prêcha un évangile de la prospérité. La réception de cet évangile a provoqué en Grande-Bretagne une vive controverse à cause de sa dérive capitaliste occidentale. À noter également un autre chapitre (Babatunde Adedibu) qui analyse l'«épidémie» de cas de sorcellerie et de maltraitance d'enfants qui ont eu lieu en Grande-Bretagne dans la population appartenant à des Églises résultant d'une fusion entre le pentecôtisme africain et certaines croyances africaines originaires. Le dernier cas (Janice McLean-Farrell) est une comparaison de la dimension religieuse de la jeunesse afro-caribéenne de Londres et de celle de New York; ces jeunes gens arrivent à atteindre à travers la religion pentecôtiste les outils pour construire leur identité collective et pour naviguer dans leur contexte social.

Outre le dernier chapitre, d'autres sont également situés dans les Amériques, à la fois dans le Nord et le Sud. Dans un chapitre (Géraldine Mossière) concernant Montréal, on nous montre comment les jeunes Congolais pentecôtistes souffrent d'une minorisation sociale double, en tant qu'Africains et en tant que membres d'une Église non catholique, ce qui les conduit à adopter des formes complexes d'appartenance. Enfin, en ce qui concerne le continent américain, on trouve deux chapitres sur le Brésil. Le premier (Bettina E. Schmidt) est une approche du processus par lequel l'Afrique devient la source ultime d'authenticité dans certaines religions afro-brésiliennes. Et l'autre chapitre (Laura Premack) offre une comparaison entre les deux grandes Églises pentecôtistes du Nigeria et du Brésil dont la présence globale est bien établie, à la fois par la construction de centres et à travers les médias. 
5 Le seul chapitre situé en Asie (Heidi Østbø Haugen) montre comment le christianisme, qui gagne en popularité en Chine, le fait en dehors des associations religieuses supervisées par l'État chinois.

6 Le livre contient également deux autres chapitres. Le premier (Asebe Regassa et Meron Zeleke) fait référence à la renaissance des pratiques culturelles traditionnelles des différents groupes ethniques de l'Éthiopie à partir des changements politiques des années 1990. Il analyse en particulier les fonctions d'un rituel des Oromo dans la diaspora, fonctions bien différentes de celles qu'il prend en Éthiopie. L'autre chapitre (Henrietta M. Nyamnjoh) est une analyse des fonctions exercées par la religion dans le processus de migration; cette analyse se centre sur l'émigration par bateau depuis le Sénégal vers les îles Canaries et, en particulier, sur le rôle joué par les marabouts, qui développent d'importants liens entre ceux qui migrent et ceux qui restent au Sénégal.

7 Ce livre est d'une grande richesse, il nous permet de visiter une grande variété de cas, et de réfléchir à l'impossibilité de construire une typologie fermée des mouvements religieux. Les possibilités de formulation d'un modèle théorique fermé de ces mouvements sont nulles. L'ouvrage nous présente une très longue série de fonctions non strictement religieuses accomplies par ces mouvements.

8 Les sciences sociales ont une grande difficulté à penser la religion comme quelque chose qui ne soit pas séparé de la culture et d'autres institutions sociales (la politique, la culture, la science...). La non-différenciation et la fluidité de la religion dans les sociétés du Sud, produisent des difficultés à comprendre le rôle de cette institution dans ces populations. Et les difficultés augmentent quand ces populations viennent s'installer dans les sociétés occidentales, sociétés où un processus de différenciation sociale a eu lieu au cours de leur histoire.

9 En montrant les nombreuses fonctions que la religion peut jouer, le livre est un contrepoint fort à la théorie de la sécularisation dans sa forme classique, comme une théorie qui a prédit l'incompatibilité entre religion et modernité. D'une part, parce que certaines populations du Sud utilisent une voie religieuse pour atteindre la modernité. D'autre part, parce que les vieilles sociétés occidentales modernes sont, aujourd'hui, de plus en plus traversées par une pluralité de cultures et de religions. Dans ces derniers pays, le processus de construction d'un État démocratique avait produit une certaine et relative, bien sûr - homogénéité culturelle et religieuse, à quelques exceptions près, comme les États-Unis.

10 De nos jours la capacité des États à être la grande structure de contrôle social général est entravée en raison de la puissance économique des grandes entreprises multinationales ainsi que par la création d'unités politiques supranationales comme l'Union européenne. La forte croissance de l'immigration en Europe après les deux guerres mondiales, liée à l'affaiblissement de la capacité de l'État à contrôler les mécanismes publics de l'intégration sociale (système de l'éducation et marché du travail) a produit une conséquence très importante: la religion des populations d'origine immigrante - minorisées du point de vue social - devient pour elles un instrument très utile pour la vie sociale.

11 Le livre met en lumière une variété de fonctions de la religion. Beaucoup sont liées à l'identité : en relation avec les origines de la population, ou avec la récupération de la tradition ou bien encore avec l'objectif de construire une identité politique différente de la dominante dans leur société d'origine ou une communauté avec des objectifs très 
pragmatiques. Certains mouvements tentent de proposer une alternative chrétienne non occidentale, ou de développement d'une idée de l'Afrique comme seule source d'authenticité et de légitimité. D'autres sont un outil pour produire l'estime de soi et l'estime sociale. Enfin, un mouvement religieux peut être une forme clandestine pour empêcher le contrôle politique de l'État (c'est le cas de la Chine).

Ce livre aurait eu davantage d'impact académique, social et politique dans les sociétés d'accueil de l'immigration si l'éditeur avait ajouté un dernier chapitre de conclusions théoriques, montrant la capacité de transformation et d'adaptation des institutions religieuses en situation de minorité sociale. Je pense que la façon la plus utile de développer la théorie sociale de la religion est d'aller vers une théorie fondamentalement analytique, afin de nous aider à concevoir des instruments de plus en plus fins pour analyser l'immense variété de formes et de fonctions que la religion peut développer dans les sociétés contemporaines.

Du point de vue académique, ce livre est riche et utile pour tous ceux qui travaillent sur la religion. Pour les universitaires africains bien sûr et pour les chercheurs qui s'occupent de la situation de la religion dans les sociétés occidentales, car l'ouvrage nous permet de repenser l'idée de laïcité. La question de la laïcité n'est plus ce qu'elle a été historiquement : dans les sociétés européennes occidentales, l'idée est née au cours du processus de démocratisation de l'État, ce qui exigeait une séparation progressive de la légitimité religieuse de l'Ancien Régime. La politique devait être libérée de la surveillance exercée par l'Église prévalente sur le territoire.

De nos jours, penser la laïcité doit nous conduire à une reformulation plus complexe, valable pour des sociétés où la religion peut jouer un rôle positif pour les populations minoritaires d'origine immigrante, où elle peut devenir la seule source d'identité positive et d'estime (de soi et sociale) que ces populations aient dans leurs mains. Si nous regardons les deuxième et troisième générations de ces populations, nous voyons des citoyens, conformément au jus soli. Mais l'État n'est plus capable, en particulier dans les périodes de crise économique, de faire fonctionner pour eux les mécanismes publics d'intégration cités ci-dessus. Beaucoup de jeunes deviennent parties intégrantes de groupes religieux qui les aident à naviguer sur les terrains symbolique et pratique. 